\title{
Information professionals to serve academia ${ }^{1}$
}

\author{
Roger Schonfeld \\ Ithaka $S+R$, New York, NY, USA \\ E-mail: Roger.schonfeld@ithaka.org
}

Like the papers presented by the panel on the Information Industry, my focus too is on the needs of a specific sector. For academia, information professionals serve the research, instructional and learning needs that present themselves at colleges and universities. The academic sector's needs for information support services are today changing no less than those of many other sectors and this change will accelerate. Information professionals must be prepared for new methods and practices of research, teaching and learning, for which their role in supporting them is changing significantly.

\section{Academia}

Compared with other sectors of the information environment that have seen profound change over the past 20 years, academia has remained relatively stable. Research funding bodies have maintained or even increased their support and student and family demand has allowed tuitions to continue to rise faster than inflation. Still, the last several years of reduced public funding have been especially challenging, and seemingly in parallel a great deal of attention has been given to a variety of models that would deliver instruction outside of a traditional campus construct.

A variety of different types of organizations are continuing to develop such models, which have included everything from conveniently located commercial learning centers to a variety of types of online and distance learning. At selective universities, comparatively tentative courseware approaches seem to be giving way to certificate-awarding courses and programs. Will credits and even degrees follow?

It is too soon to know what ventures can emerge successfully from this period of innovation, rapid prototyping and willingness to fail. Some observers see the same stable higher education system we have had for 100 years; others see an information industry blind to the disruptive forces that are massing at the gates. Looking forward to 2050, to the extent we can, suggests a need to engage structural unknowns of this type.

What types of information structures and roles would be needed by a disrupted higher education environment? How would reconfigurations in research and teaching roles and responsibilities, within and across educational institutions, affect the demand for and organization of information support services? Those interested in considering a career in academia may benefit from having a framework for considering the types of environmental change that may affect academia as they understand it today.

\footnotetext{
${ }^{1}$ This work is licensed under the Creative Commons Attribution-Noncommercial No Derivations Works 3.0 Unported license. You are free to Share this work (copy, Distribute and transmit) under the following conditions: attribution, noncommercial and no derivative works. To view a copy of this license, visit http://creativecommons.org/licenses/by-nc-sa/3.0/.
} 


\section{Research practices and support}

These structural shifts driven by changing methods of organizing and delivering instruction may seem speculative, but the changes in research methods and practices are not. Among those trends that may prove to have greatest significant for information support providers include:

- Primary research materials are becoming increasingly readily available online in essentially all fields, as previously happened for many secondary and reference sources.

- Computational methods are blossoming in many fields, changing the very nature of the types of research questions that can be feasibly pursued in the course of one's career.

- Research practices are changing even more dramatically as new tools and processes make it possible for scholarship to be conducted with greater efficiency.

To understand the types of changes that are taking place, information professionals must be prepared to engage at the right level of community for the services required. In the case of academia, the key level of community around which research methods and practices are organized is at the discipline- or perhaps field-specific level.

For this reason, Ithaka S+R's Research Support Services for Scholars program area is organized around focused studies of individual academic disciplines, beginning with core fields such as history and chemistry. In these studies, we are taking a scholar-centric perspective. To do so, we recognize that we cannot simply ask scholars and students what they would like to have in terms of information services and support; but rather we must understand their actual practices and how these practices are changing. In engaging the disciplines' changing research methods and practices through these projects, my colleagues and I are analyzing the types of research support services that scholars individually and their fields collectively will benefit from having available to them.

With a list of research support services needs, these projects will ultimately position the community to consider the types of information services organizations that are best positioned organizationally and substantively to provide a given service. For example, any given service might be best provided by a library, or a scholarly society, or a research-computing center, or a publisher, or some combination of them. If our premise that discipline- and field-specific needs will drive distinctive services requirements is correct, then something other than centralized campus-level services development and delivery will be required. And, field-specific offerings may not always be constrained to a single university but may sometimes be provided across institutional boundaries.

A basic prerequisite is to identify services that offer value to researchers, and then to position existing service providers and new ones alike to put their resources towards these valued services to the greatest extent possible. How can information professionals be most effectively prepared to balance a scholarcentric perspective against an organizational approach in planning their work?

\section{Attributes and skills}

In addition to some of the ideas mentioned above, some key attributes and skills that we may want to consider information professionals requiring today or going forward will mostly allow them to adapt given an environment of uncertainty:

- An understanding of how to incorporate diverse sources of data in appropriate ways into strategic and services planning and development, and where to gather such data when it does not exist. Every information professional should be expected to have basic skills and positive instincts in these areas. 
- An ability to consider the organizational interests of relevant entities in developing and planning strategies, programs, and services. Perhaps first among these is the information organization (the library) itself alongside its college/university setting, each of which has values, priorities, and real interests. Concern for the needs of the parent organization, in a period where some of them could face real trauma and others unimagined opportunities, is especially needed. Partners and vendors are often trusted too much or too little; how can information professionals develop the right level of scrutiny to inform appropriate degrees of trust and dependency?

- Information professionals should be comfortable engaging - deeply, regularly and creatively - with the individual users and user communities that they support. Softer or perhaps even innate skills, such a confidence in building a relationship with a professor and curiosity in attending the annual meeting of the academic scholarly society, are perhaps always valuable. Harder skills, such as advanced training in the appropriate academic field, may also be beneficial. 